\title{
Different Device Architectures for Bulk-Heterojunction Solar Cells
}

\author{
Getachew Adam ${ }^{1}$, Battulga Munkhbat' ${ }^{2}$ Patrick Denk ${ }^{1}$, Christoph Ulbricht ${ }^{1}$, \\ Calin Hrelescu ${ }^{2}$ and Markus C. Scharber ${ }^{1 *}$
}

${ }^{1}$ Linz Institute for Organic Solar Cells, Johannes Kepler University Linz, Linz, Austria, ${ }^{2}$ Institute of Applied Physics, Johannes Kepler University Linz, Linz, Austria

\section{OPEN ACCESS}

Edited by:

Theodoros Dimopoulos, Austrian Institute of Technology, Austria

Reviewed by: Josep Albero, Institute of Chemical Technology (CSIC-UPV), Spain Ioanna Giouroudi, Vienna University of Technology, Austria

*Correspondence:

Markus C. Scharber markus_clark.scharber@jku.at

Specialty section: This article was submitted to Translational Materials Science, a section of the journal

Frontiers in Materials

Received: 12 April 2016 Accepted: 29 July 2016 Published: 23 August 2016

Citation: Adam G, Munkhbat B, Denk P, Ulbricht $C$. Hrelescu $C$ and Scharber MC (2016) Different Device Architectures for BulkHeterojunction Solar Cells.

Front. Mater. 3:39. doi: 10.3389/fmats.2016.00039
We report different solar cell designs which allow a simple electrical connection of subsequent devices deposited on the same substrate. By arranging the so-called standard and inverted solar cell architectures next to each other, a serial connection of the two devices can easily be realized by a single compound electrode. In this work, we tested different interfacial layer materials, such as polyethylenimine and PEDOT:PSS, and silver as a non-transparent electrode material. We also built organic light-emitting diodes applying the same device designs demonstrating the versatility of applied layer stacks. The proposed design should allow the preparation of organic bulk-heterojunction modules with minimized photovoltaically inactive regions at the interconnection of individual devices.

Keywords: bulk-heterojunction solar cell, interlayer, module design, photovoltaics, solar energy

\section{INTRODUCTION}

Due to their favorable properties and simple manufacturing organic photovoltaic devices (OPV) such as bulk-heterojunction solar cells $(\mathrm{BHJ})$ are promising candidates for the efficient conversion of solar radiation into electricity. BHJ solar cells can be solution processed or printed in a roll-toroll fabrication scheme, they can be light-weight and flexible and have the potential to become a truly low-cost PV technology (Machui et al., 2014; Rand and Richter, 2014) The power conversion efficiency of OPV devices has increased from around $1 \%$ to over $11 \%$ in the past 15 years (Scharber, 2016; Zhao et al., 2016). Especially, the design of new organic semiconductors and the control of the molecular arrangement of the donor and acceptor components in the absorber layer lead to the tremendous improvement of the device performance (Xu and Yu, 2014; Etxebarria et al., 2015). It is believed that the achieved power conversion efficiencies are already sufficient for the implementation of OPVs into products (www.solarte.de). Due to their mechanical properties and their low weight especially portable applications are considered as promising candidates for the first commercialization phase of BHJ. As the voltage delivered by a single solar cell (typically in the range of $0.5-1 \mathrm{~V}$ ) is usually not sufficient to recharge batteries or to power even very small devices, several solar cells have to be connected in series to obtain the desired output voltage. This is usually achieved by connecting the top electrode of the first device to the bottom electrode of the second device and so on. Figure 1A displays the connection scheme often called monolithic interconnection (Markvart and Castaner, 2005). The layer stack of the cells used in this module design is the so-called standard device layout of organic solar cells. The transparent electrode in combination with a transparent interlayer forms the anode of the device. The top electrode comprising a combination of an interlayer and a metal layer serves as the cathode. The main disadvantage of this configuration is that the spacing between two solar cells needs to be relatively wide to ensure a sufficient overlap of the two contacts and a low 


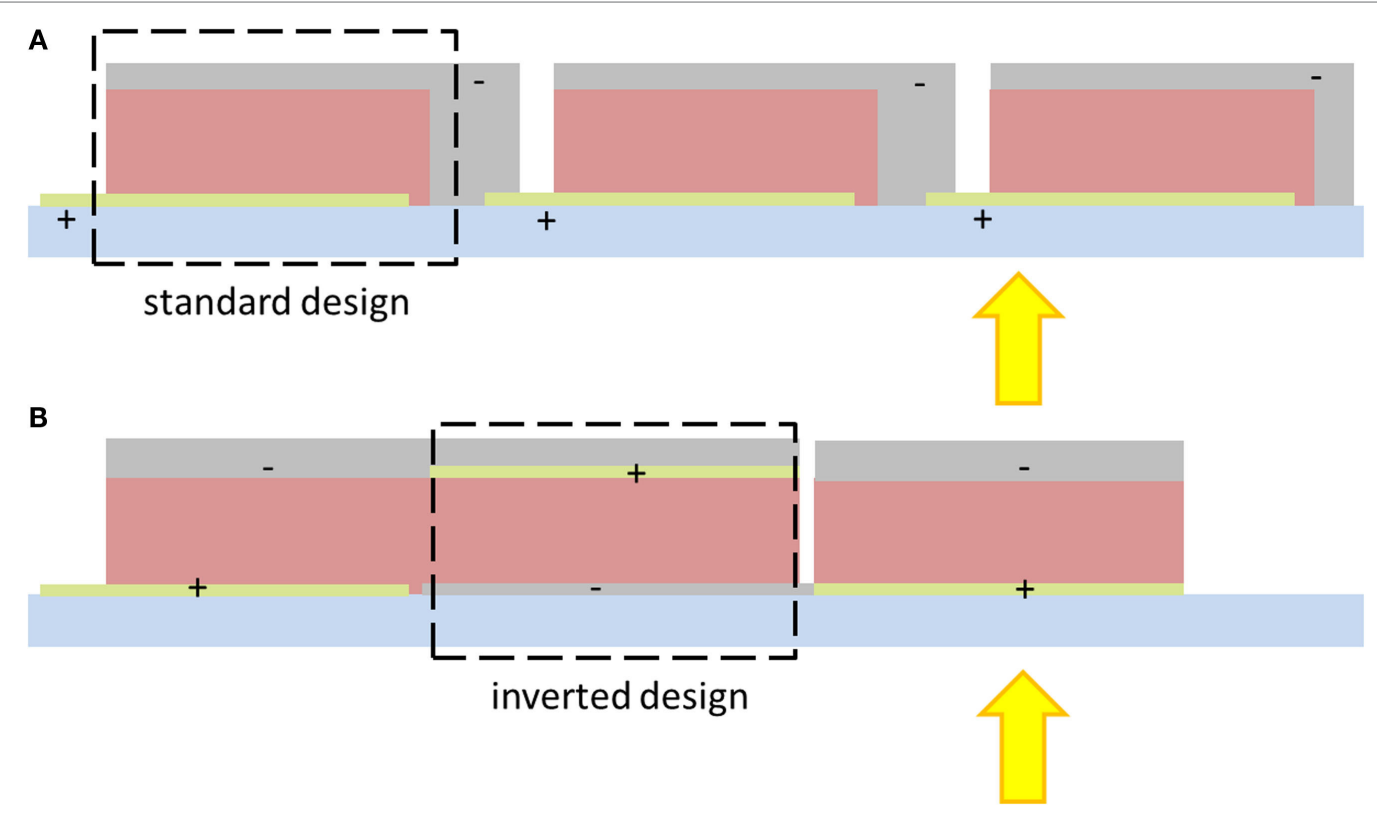

FIGURE 1 | (A) Monolithic module interconnection and (B) alternative module design.

contact resistance. The area required for interconnects does not produce any photocurrent and does not contribute to the power conversion of the module. Therefore, it should be as small as possible. An alternative connection scheme is shown in Figure 1B (Gaudian, 2010; Lee et al., 2012, 2013). Solar cells with alternating electrode polarity are deposited on a carrier substrate.

Individual cells are connected by extending the top/bottom electrode layer to the neighboring solar cell. This design has favorable electrical properties and the spacing between solar cells, i.e., the inactive module area can be very small. The standard device stack is often made of the following layers: a transparent electrode layer over-coated with PEDOT:PSS (poly(3,4-ethylenedioxythiophene):poly(styrenesulfonate)), followed by the photoactive layer and a metal electrode with a low work function. The inverted device comprises a transparent electrode, an interlayer which forms an electron-selective contact to the photoactive layer [e.g., zinc oxide $(\mathrm{ZnO})$ or titanium oxide $\left(\mathrm{TiO}_{\mathrm{x}}\right)$ ] (Waldauf et al., 2006) or converts the transparent electrode into electron-selective contact (e.g., polyethyleneimine) (Zhou et al., 2012; Udum et al., 2014). On top of the interlayer, the photoactive layer is deposited followed by a hole-selective interlayer [PEDOT:PSS or molybdenum oxide $\left(\mathrm{MoO}_{\mathrm{x}}\right)$ ] and a metal electrode.

The inverted device design offers many advantages including improved device stability when exposed to ambient conditions. In the standard design, often a low work-function metal is required as top electrode (e.g., calcium or aluminum) which oxidizes quickly in the presence of oxygen and/or water. By contrast, high work-function metals such as silver or gold can be used for the hole-selective metal top electrode in inverted solar cells. Fully printed inverted devices have been demonstrated which turned out to be very difficult for the standard device design (Krebs, 2008).
In this contribution, we summarize our work on different device designs which could be applied to realize simple interconnects between individual solar cells. We used PEDOT:PSS or $\mathrm{MoO}_{\mathrm{x}}$ as hole-selective interlayers, and polyethylenimine (PEI) to modify indium tin oxide (ITO) electrodes into electron-selective contacts. As absorber materials, we applied a blend of poly(3hexylthiophene-2,5-diyl) (P3HT) and different fullerene derivatives. The overall goal was to realize a set of interconnected solar cells following the scheme illustrated in Figure 1B, which can be manufactured using printing and coating methods. All processes should be compatible with flexible polymeric substrates such as polyethylene terephthalate (PET). In the performed experiments, we use blade coating and spin coating for the deposition of the interlayers and the absorber layer. $\mathrm{MoO}_{\mathrm{x}}$ and metal electrodes were thermally deposited. This process may be compatible with roll-to-roll deposition or one may apply silver-pastes or nanowire materials as the top-contact electrode layer. We also built organic light-emitting diodes applying the same device designs to demonstrate the versatility of applied layer stacks and to learn more about the limitations of the investigated interfacial layers.

\section{EXPERIMENTAL SECTION}

Regio-regular poly(3-hexylthiophene-2,5-diyl) (P3HT, Rieke Metals), [6,6]-phenyl-C61-butyricacidmethylester(PCBM), bis(1[3-(methoxycarbonyl)propyl]-1-phenyl)-[6,6]C62 (bis-PCBM) (Solenne BV), PEI (branched, $M_{\mathrm{w}}=800 \mathrm{~g} \mathrm{~mol}^{-1}$, Sigma Aldrich), poly (3,4-ethylenedioxythiophene):poly(styrenesulfonate) (PEDOT:PSS, Clevios PH 1000, and PVP Al 4083, Heraeus), Zonyl ${ }^{\circledR}$ FS-300 fluorosurfactant (40\% in $\mathrm{H}_{2} \mathrm{O}$, Fluka), dimethyl sulfoxide (DMSO, Anal R, VWR chemicals), and poly(2-methoxy-5-(2-ethylhexyloxy)-1,4-phenylene-vinylene) (MEH-PPV) 
end capped with polysilsesquioxane (POSS)-coded ADS200RE $\left(M_{\mathrm{w}}=100,000 \mathrm{~g} \mathrm{~mol}^{-1}\right.$, American Dye Source Inc.) were used as received without further purification. The chemical structures of the used organic semiconductors and interlayer materials are shown in Figure 2. All manipulations for the fabrication of devices were performed in ambient atmosphere if not stated otherwise. For the fabrication of either standard or inverted $\mathrm{BHJ}$, solutions of P3HT:PCBM and P3HT:bis-PCBM (1:0.8 and 1:1 weight ratio, respectively) were prepared in chlorobenzene $\left(40 \mathrm{mg} \mathrm{ml}^{-1}\right)$. For OLEDs, the orange-emitting polymer ADS200RE was dissolved in chlorobenzene $\left(8 \mathrm{mg} \mathrm{ml}^{-1}\right)$. Prepatterned glass/ITO and bare glass substrates were cleaned by ultrasonication in acetone, isopropanol, Helmanex ${ }^{\circledR}$ detergent, and deionized water successively. Flexible ITO-coated PET substrates were cleaned using, isopropanol, Helmanex ${ }^{\circledR}$ detergent, and deionized water successively. PEDOT:PSS (Clevios PH1000, 5\% DMSO, 0.7 vol\% Zonyl) was spin coated at $1000 \mathrm{rpm}$ for
$60 \mathrm{~s}$, patterned and annealed at $140^{\circ} \mathrm{C}$ for $10 \mathrm{~min}$, then rinsed with isopropanol to remove the excess Zonyl, and then annealed for another $10 \mathrm{~min}$ at $140^{\circ} \mathrm{C}$. For all inverted devices, PEI in $n$-butanol $\left(0.27 \mathrm{mg} \mathrm{ml}^{-1}\right)$ was spin coated on top of cleaned and $\mathrm{O}_{2}$-plasma-treated glass/ITO, PET/ITO, and PEDOT:PSS (Clevios PH 1000, 5\% DMSO, 0.7 vol\% Zonyl)-coated glass substrate at $3000 \mathrm{rpm}$ and then annealed on a hot plate $\left(105^{\circ} \mathrm{C}\right.$ for $10 \mathrm{~min})$. After cooling down, P3HT:PCBM or P3HT:bis-PCBM solution for OPVs and ADS200RE solution for OLEDs was spin coated on top of PEI. A layer of PEDOT:PSS (Clevios PVP Al $4083,0.7 \mathrm{vol} \%$ Zonyl) was spin coated on top of the active layer and then annealed at $110^{\circ} \mathrm{C}$ for 20 min inside a glove box (dry $\mathrm{N}_{2}$ atmosphere), or $\mathrm{MoO}_{\mathrm{x}}(10 \mathrm{~nm})$ was deposited via thermal evaporation before the devices were finalized by the deposition of a silver electrode (ca. $100 \mathrm{~nm}$ ).

For the standard device, low conductivity PEDOT:PSS PVP $\mathrm{Al} 4083$ was spin coated onto the cleaned ITO followed by the

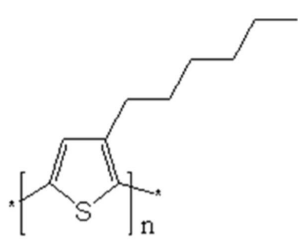

P3HT

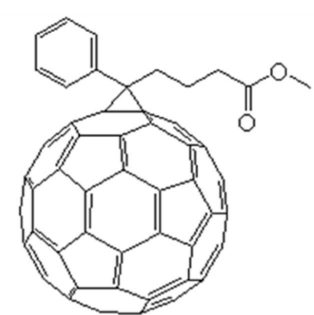

PCBM

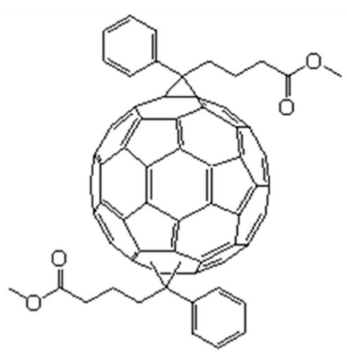

Bis-PCBM<smiles>CC(C)CN(CCNCCN(C)CCN(C)CCN(CCN)CCN)CCN(C)CCN</smiles>

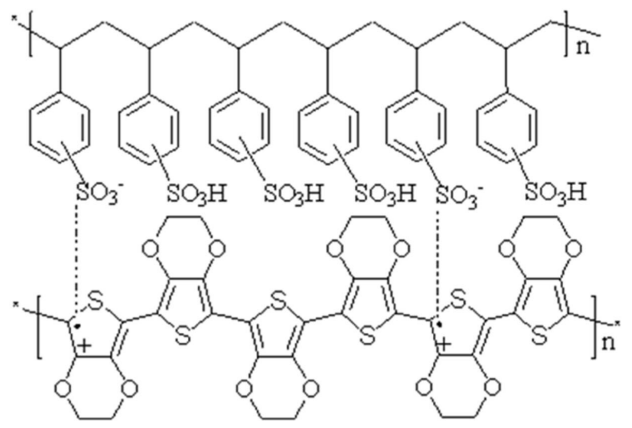

PEDOT:PSS

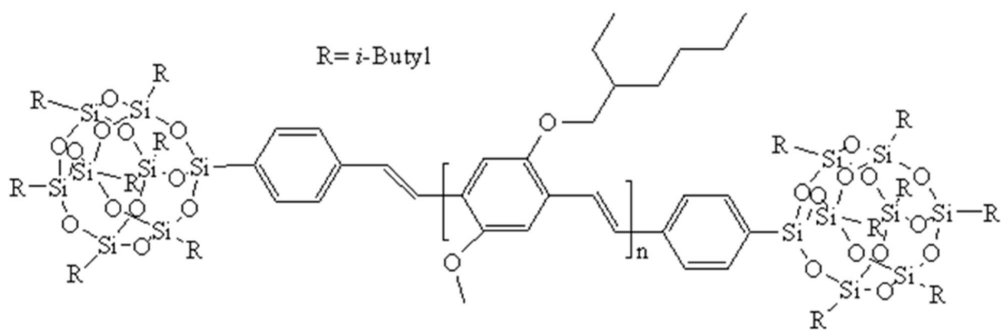

ADS200RE

FIGURE 2 | Photoactive and interlayer materials. 
deposition of the active layer. In the next step, samples were transferred into a glove box and annealed for $10 \mathrm{~min}$ at $120^{\circ} \mathrm{C}$ (OPVs) and $90^{\circ} \mathrm{C}$ (OLEDs). Standard OPVs and OLEDs were completed by vacuum evaporation $\left(\sim 3 \times 10^{-6}\right.$ bar $)$ of the top contact $[0.8 \mathrm{~nm}$ $\mathrm{LiF}$ and $100 \mathrm{~nm}$ aluminum (OPVs), or $20 \mathrm{~nm}$ of calcium and $100 \mathrm{~nm}$ of silver (OLEDs)].

For blade-coated devices, pre-patterned glass/ITO substrates were cleaned, as described earlier. For the inverted solar cells, PEI $\left(0.27 \mathrm{mg} \mathrm{ml}^{-1}\right.$ dissolved in butanol) was coated on a heated substrate $\left(70^{\circ} \mathrm{C}\right.$, blade speed of $\left.5 \mathrm{~mm} \mathrm{~s}^{-1}\right)$. The PEI-film was dried at $105^{\circ} \mathrm{C}$ on a hot plate for $10 \mathrm{~min}$ before the deposition of the photoactive layer. For standard devices, PEDOT:PSS (PVP Al 4083 ) diluted with water (1:2 volume ratio) was coated on a heated substrate $\left(70^{\circ} \mathrm{C}\right.$, blade speed of $\left.5 \mathrm{~mm} \mathrm{~s}^{-1}\right)$. The absorber layer solution [P3HT $\left(12 \mathrm{mg} \mathrm{ml}^{-1}\right)$ and PCBM $\left(8 \mathrm{mg} \mathrm{ml}^{-1}\right)$ dissolved in chlorobenzene] was blade coated on a heated substrate coated with PEI or PEDOT:PSS $\left(75^{\circ} \mathrm{C}\right.$, blade speed of $\left.15 \mathrm{~mm} \mathrm{~s}^{-1}\right)$. Inverted devices were finalized with the deposition of $\mathrm{MoO}_{\mathrm{x}}(10 \mathrm{~nm})$ and silver $(100 \mathrm{~nm})$. For another standard devices layout, a thin layer of a PEI:PCBM blend [ $1 \mathrm{mg} \mathrm{ml}^{-1}$ PCBM, $0.8 \mathrm{mg} \mathrm{ml}^{-1}$ PEI dissolved in a butanol/anisole solution (19:1 volume ratio)] was coated on top of the photoactive layer at a temperature of $80^{\circ} \mathrm{C}$ and a blade speed of $10 \mathrm{~mm} \mathrm{~s}^{-1}$. These standard devices were finalized with a silver electrode $(100 \mathrm{~nm})$ deposited by thermal evaporation.

Current density-voltage $(\mathrm{J}-\mathrm{V})$ characteristics were measured under AM 1.5 white light illumination $\left(100 \mathrm{~mW} \mathrm{~cm}^{-2}\right.$ solar simulator) using a Keithley 2400 Source-Meter-Unit. External quantum efficiency (EQE) measurements were conducted using $90 \mathrm{~W}$ Xenon lamp as light source connected via an optical fiber to an ACTON Spectra Pro150 monochromator and an EG\&G
7260 DSP Lock-in amplifier. The performance of the fabricated OLEDs was measured using an Agilent B1500 parameter analyzer with two source meter units, one driving the OLED and one measuring the resulting photocurrent of a silicon photodiode. The electroluminescence (EL) spectra of OLEDs were recorded using a Photo Research Spectra scan PR-655 CCD camera and by applying constant current density with Keithley SMU 2401.

\section{RESULTS AND DISCUSSION}

Figure 3 shows all the device stacks prepared in this study. Figure 3E illustrates the realized alternative interconnection of two solar cells with alternating polarities. The performance of the different solar cells is discussed below in detail. In addition, we built light-emitting diodes based on the layer stacks (Figures 3A-D). Although we found that the performance of all inverted OLEDs is significantly reduced compared with the reference device, it is interesting to see that all tested configurations allow the preparation of working devices. The luminance-current density-voltage (L-J-V) curves are also shown below for the different device designs.

\section{ITO as an Electron-Selective Electrode and $\mathrm{MoO}_{\mathrm{x}}$ as a Hole-Selective Layer}

Figure $4 \mathrm{~A}$ shows the $\mathrm{J}-\mathrm{V}$ curves of standard OPV devices with the layer stack glass/ITO/PEDOT:PSS/P3HT:PCBM or bis-PCBM/LiF/Al (Figure 3A). In Figure 4B, the J-V curves of inverted devices (Figure 3B) with the structure glass/ITO/PEI/ P3HT:PCBM or bis- $\mathrm{PCBM} / \mathrm{MoO}_{\mathrm{x}} / \mathrm{Ag}$ are plotted. The inverted and standard devices showed comparable diode dark currents,

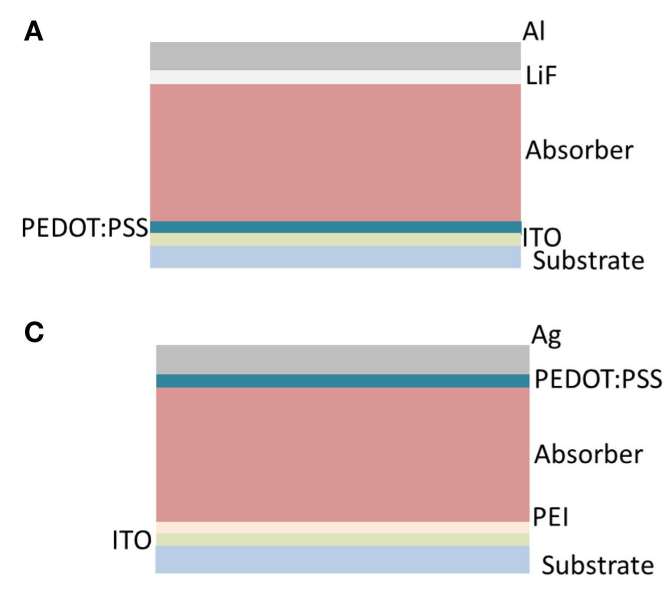

B

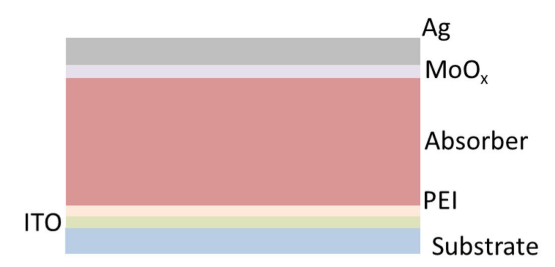

D

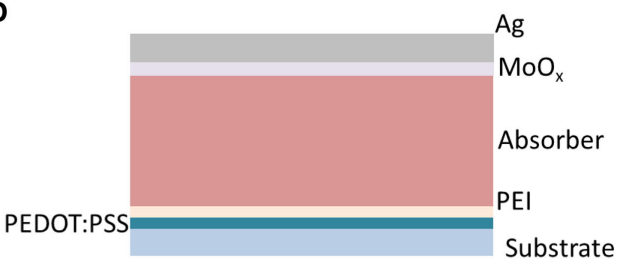

E

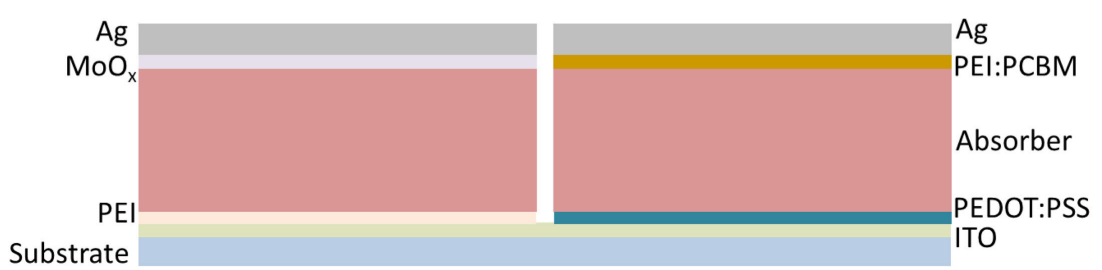

FIGURE 3 | (A) Standard device (reference), (B) inverted device with $\mathrm{MoO}_{\mathrm{x}}$ as hole-selective interlayer, (C) inverted device with PEDOT:PSS as hole-selective interlayer, (D) inverted device with PEDOT:PSS as electron-selective interlayer, (E) inverted and standard device connected through the ITO electrode. 

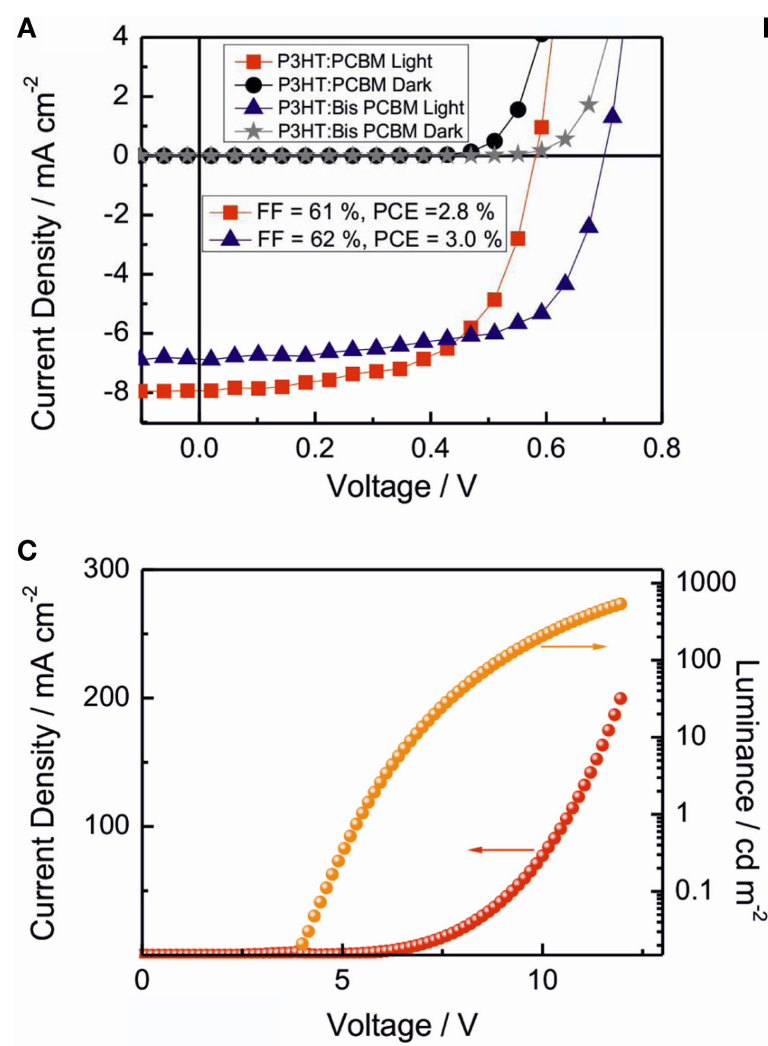

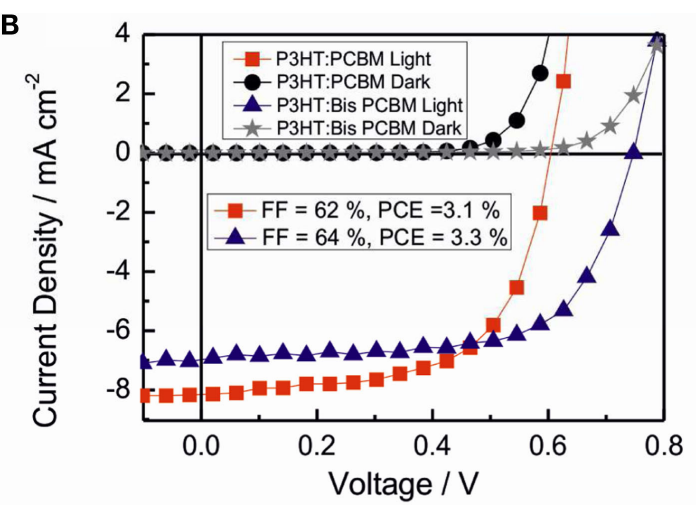

D

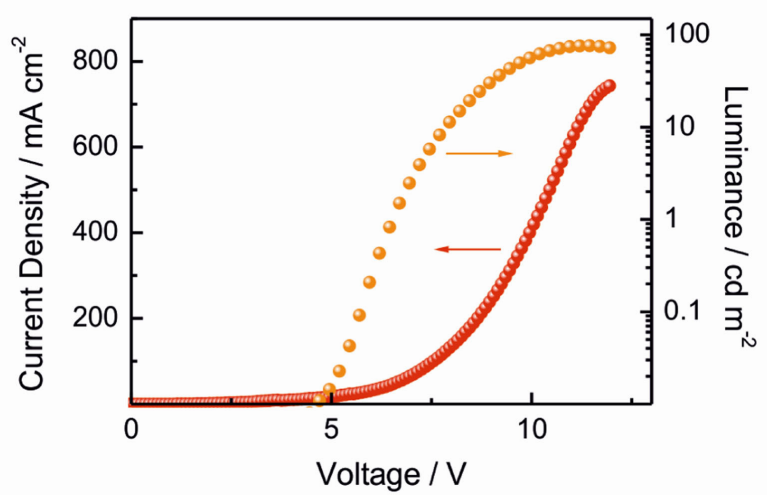

FIGURE 4 | J-V and L-J-V characteristics of standard and inverted BHJ OPVs and OLEDs: (A) glass/ITO/PEDOT:PSS/P3HT:PCBM or bis-PCBM/LiF/ Al, (B) glass/ITO/PEI/P3HT:PCBM or bis-PCBM/MoO ${ }_{x} / \mathrm{Ag}$, (C) glass/ITO/PEDOT:PSS/ADS200RE/Ca/Ag, and (D) glass/ITO/PEI/ADS200RE/MoO $/$ /Ag configurations, respectively.

short circuit currents, and fill factors. For inverted devices, slightly higher open-circuit voltages and electrical fill factors (FF) were found yielding about $10 \%$ higher power conversion efficiencies. It is interesting to note that the ITO/PEI electrode can form excellent contacts to fullerene derivatives with different electron affinities (Lenes et al., 2008).

The L-J-V characteristics of ADS200RE-based OLEDs prepared in the standard and inverted configuration are illustrated in Figures 4C,D. Both devices exhibit similar onset and operating voltages. However, a lower luminance of $\sim 58 \mathrm{~cd} \mathrm{~m}^{-2}$ at $10 \mathrm{~V}$ and a maximum luminance of $\sim 80 \mathrm{~cd} \mathrm{~m}^{-2}$ were found in the inverted OLEDs, while the standard OLEDs showed $208 \mathrm{~cd} \mathrm{~m}^{-2}$ at $10 \mathrm{~V}$ and highest luminance of $\sim 847 \mathrm{~cd} \mathrm{~m}^{-2}$. These findings illustrate that the $\mathrm{PEI} / \mathrm{MoO}_{\mathrm{x}}$ interlayers are not ideal for the selected polymer emitter. Despite the high injection currents found for the inverted device, the luminance is about one order of magnitude lower. This might be an indication for an unbalanced charge carrier (electrons and holes) injection into the emitter layer caused by different injection barriers formed at the interlayer-semiconductor interface. The work function of the ITO-PEI stack was found to be in the range of $3.5 \mathrm{eV}$, whereas the LUMO position of the emitter polymer is $\sim 3 \mathrm{eV}$ (Zhou et al., 2012). This large offset may be the origin of the reduced luminance of the studied inverted OLEDs.

As expected, the stability of inverted OLEDs was found to be much better compared with the standard devices with low work-function metal electrode, when operated under ambient conditions. While standard devices showed a gradual reduction of the EL and showed no emission after about 90 min of continuous operation in air, the OLEDs with the air-stable top electrodes could be operated for several hours without a significant reduction of the EL intensity.

\section{PEDOT:PSS as a Hole-Selective Layer and ITO as an Electron-Selective Electrode}

By replacing the inorganic hole-selective layer $\mathrm{MoO}_{\mathrm{x}}$ by PEDOT:PSS, efficient BHJ OPVs and OLEDs can be prepared (Figure 3C). In Figure 5A, the inverted $\mathrm{BHJ}$ with the layer sequence glass/ITO/PEI/P3HT:PCBM or bis-PCBM/ PEDOT:PSS/Ag showed photovoltaic performances comparable to solar cells with a $\mathrm{MoO}_{\mathrm{x}}$ interlayer and the reference devices (Figures 4A,B). The same device stack was also built on a flexible substrate and comparable efficiencies were found for rigid and flexible solar cells (Figures 5A,B). These results suggest that the vacuum-deposited $\mathrm{MoO}_{\mathrm{x}}$ layer can be replaced by a solutionprocessed PEDOT:PSS without significant performance losses in inverted $\mathrm{BHJ}$ solar cells.

Figures 5C,D show the characteristics of OLEDs with the layer sequence glass/ITO/PEI/ADS200RE/PEDOT:PSS/Ag and PET/ITO/PEI/ADS200RE/PEDOT:PSS/Ag, respectively. Devices 

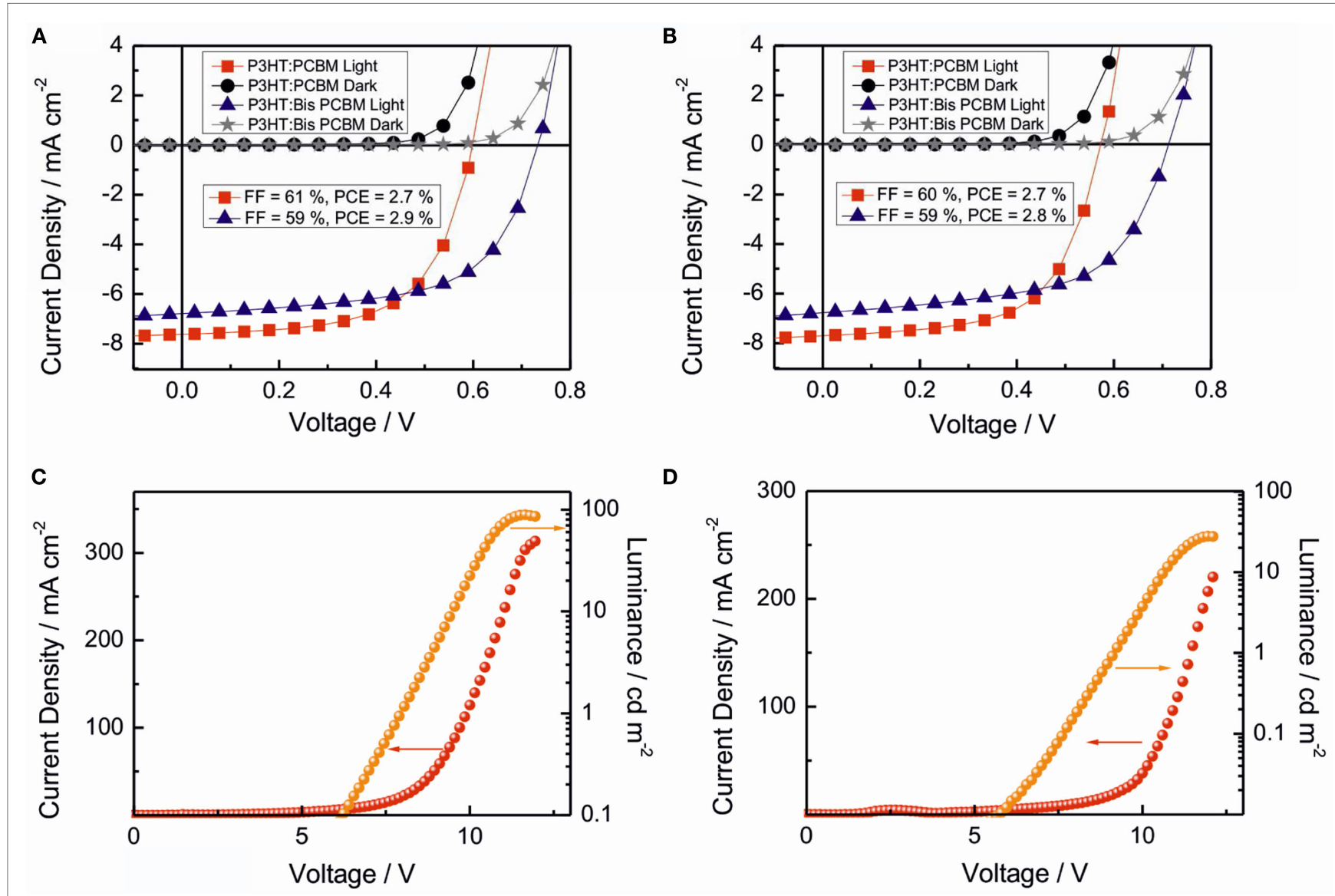

FIGURE 5 | J-V characteristics of the OPVs: (A) glass/ITO/PEI/P3HT:PCBM or bis-PCBM/PEDOT:PSS/Ag, (B) PET/ITO/PEI/P3HT:PCBM or bis-PCBM/ PEDOT:PSS/Ag and L-J-V characteristics of OLEDs: (C) glass/ITO/PEI/ADS200RE/PEDOT:PSS/Ag, and (D) PET/ITO/PEI/ADS200RE/PEDOT:PSS/Ag.

exhibited a luminance of $\sim 100 \mathrm{~cd} \mathrm{~m}^{-2}$ on glass (Figure $5 \mathrm{C}$ ) and $\sim 30 \mathrm{~cd} \mathrm{~m}^{-2}$ on PET (Figure 5D) which is comparable to the OLEDs fabricated with a $\mathrm{MoO}_{\mathrm{x}}$ layer (Figure 4D). The presented results indicate the investigated $\mathrm{MoO}_{\mathrm{x}} / \mathrm{Ag}$ and PEDOT:PSS/ Ag electrodes exhibit similar charge extraction and injection efficiencies.

Figure 6A shows the EQE spectra of flexible solar cells with PET/ITO/PEI/P3HT:PCBM or bis-PCBM/PEDOT:PSS/Ag with its maximum at $525 \mathrm{~nm}$. Figure $6 \mathbf{B}$ shows the photograph of the corresponding flexible solar cell. In Figure 6C, the normalized extinction and spectrum of the OLED with PET/ITO/PEI/ ADS200RE/PEDOT:PSS/Ag is displayed. Photographs of the corresponding flexible OLED are shown in Figure 6D. The presented results demonstrate that the explored device architectures can easily be transferred to flexible substrates.

\section{Highly Conductive PEDOT:PSS as an Electron-Selective Electrode and $\mathrm{MoO}_{\mathrm{x}}$ or PEDOT:PSS as a Hole-Selective Layer}

The second type of inverted design realized in this work is based on a high conductivity PEDOT:PSS/PEI stack used as an electron-selective electrode and $\mathrm{MoO}_{\mathrm{x}}$ (Figure 3D) or
PEDOT:PSS (Clevios PVP Al 4083) as hole selective contact. In this structure, ITO is replaced by PEDOT:PSS. A silver bus bar deposited between the substrate and the PEDOT:PSS layer can be used to support the conductivity of the semitransparent electrode. Applying PEDOT:PSS electrodes on both sides of the photoactive layer leads to a semitransparent device and a fully solution processed device stack. As shown in Figure 7A, with glass/PEDOT:PSS/PEI/P3HT:PCBM or bis-PCBM/MoO $/$ Ag stacks, reasonable solar cell performances could be achieved with good fill factor $(>60 \%)$. The smaller short circuit current density compared with the ITO-based devices might be caused by additional optical losses in the PEDOT:PSS layer.

Figure 7B shows the results obtained when using low conductivity PEDOT:PSS (Clevios PVP Al 4083) instead of MoOx. The freshly prepared device showed losses in all electrical parameters but after light soaking for $1 \mathrm{~h}$, a significant improvement in all the electrical parameters was observed. This suggests that defects or traps states are present in the as-prepared devices. Residual water which is trapped in the PEDOT:PSS layers and forming interface dipoles may be responsible for the S-shaped J-V curve observed for fresh devices. Upon long-term illumination, dipoles re-arrange and the expected J-V curve can be measured. The S-shaped 

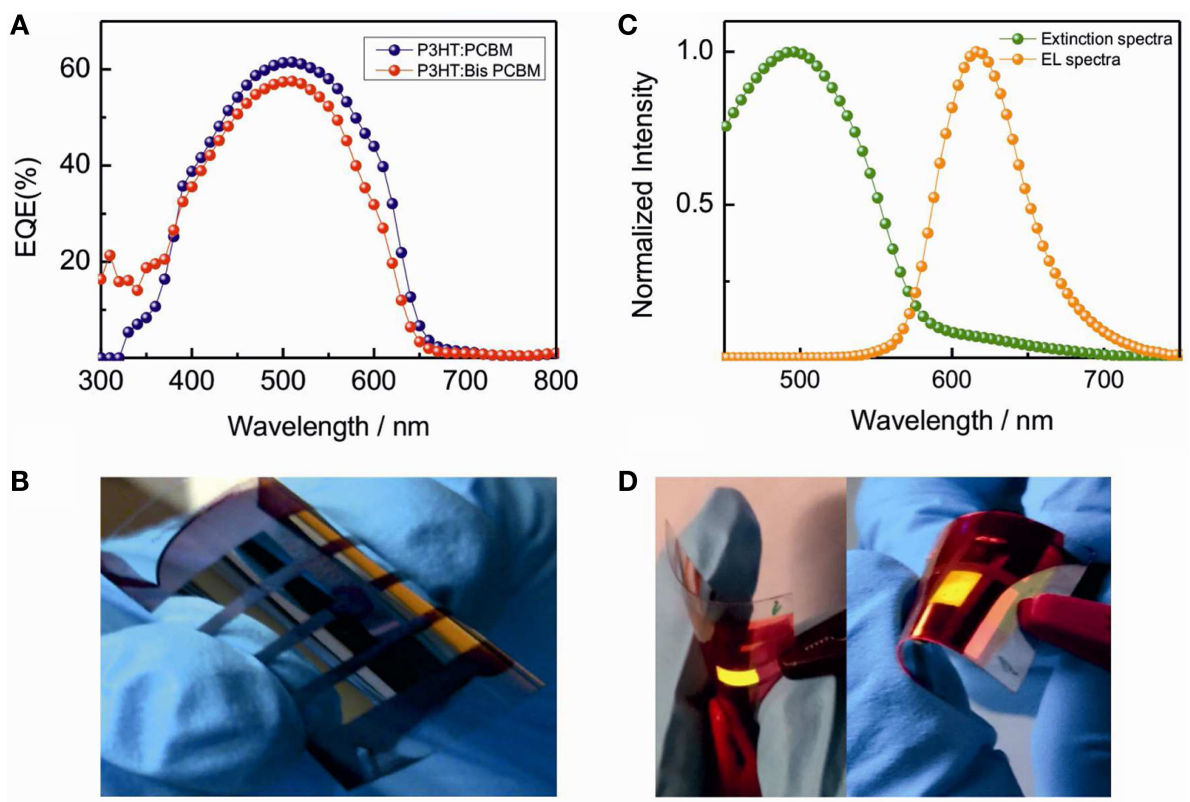

FIGURE 6 | (A,B) EQE spectra of the solar cells with PET/ITO/PEI/P3HT:PCBM or bis-PCBM/PEDOT:PSS/Ag, and the photograph of the corresponding flexible solar cell, respectively, and (C) normalized extinction and electroluminescence spectra of the OLEDs with PET/ITO/PEI/ADS200RE/PEDOT:PSS/Ag, and (D) the photograph of the corresponding flexible OLED while operated in air.
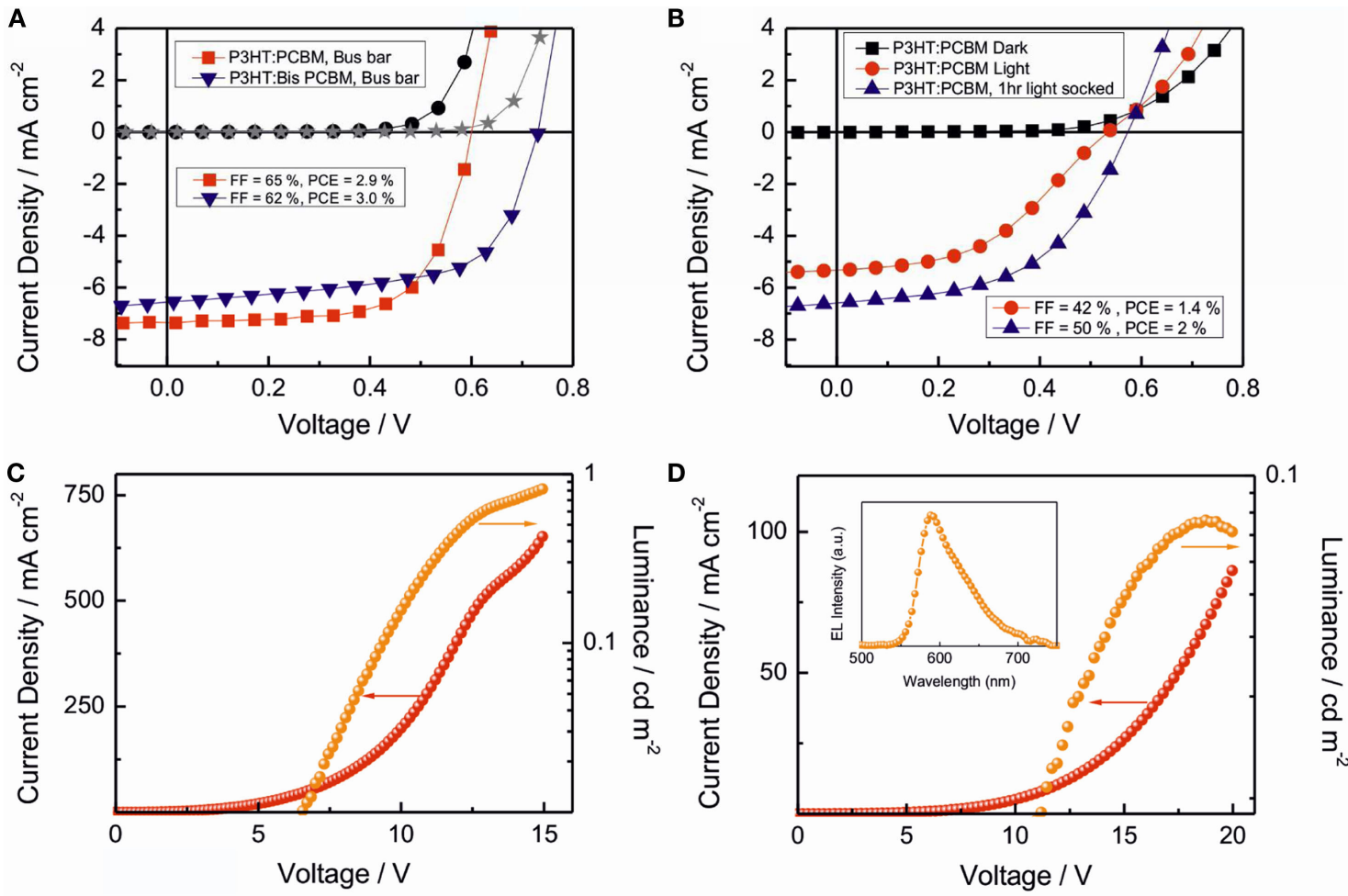

FIGURE 7 | J-V characteristics of the OPVs: (A) glass/PEDOT:PSS/PEI/P3HT:PCBM or bis-PCBM/MoO $/$ Ag, and (B) glass/PEDOT:PSS/PEI/ P3HT:PCBM/PEDOT:PSS/Ag; L-J-V characteristics of OLEDs: (C) glass/PEDOT:PSS/PEI/ADS200RE/MoOx/Ag, and (D) glass/PEDOT:PSS/PEI/ ADS200RE/PEDOT:PSS/Ag. The inset in (D) displays the EL spectrum of corresponding OLEDs. 
$\mathrm{J}-\mathrm{V}$ curve recovered when the device is stored in the dark overnight.

Prepared OLEDs exhibited, despite reasonable current densities, a much lower luminance compared to the standard OLEDs (Figure 4C). The device based on a $\mathrm{MoO}_{\mathrm{x}} / \mathrm{Ag}$ top electrode showed a luminance of $\sim 1 \mathrm{~cd} \mathrm{~m}^{-2}$ at $15 \mathrm{~V}$ (Figure 7C) while for the OLED with two PEDOT:PSS electrodes only $0.1 \mathrm{~cd} \mathrm{~m}^{-2}$ were found at very high operating voltages (Figure 7D). The relatively high onset voltage and the weak EL found in both devices suggests that the PEDOT:PSS/PEI electrode is not ideal for the injection of electrons into the emitter layer. Also unbalanced electron and hole injection and the presence of interface dipoles or traps, causing the S-shaped J-V characteristics in the corresponding solar cells, may limit the performance of the investigated OLEDs. By contrast, in solar cells, the extraction of photo-generated electrons through the PEDOT:PSS/PEI is working well. This suggests that a selective contact is formed between the tested fullerene acceptors and the cathode.

\section{PEDOT:PSS as a Hole-Selective and PCBM:PEI as an Electron-Selective Layer}

The last layer stack we tested was a standard device with high work-function top electrode (Figure 3E). In the first set of experiments, we deposited thin layers of PEI on top of the absorber layer and finished the device with a vacuum-deposited silver electrode. This approach did not result in working solar cells. Either we found non-selective contacts and the solar cells showed very small open-circuit voltages and poor diode characteristics or the contact was blocking any electrical current flow through the device. The non-selective contacts may be caused by too thin or inhomogenous PEI layers, while in the case of blocking contacts the layers were too thick. To overcome this problem, we added small amounts of PCBM to the PEI solution. With this we tried to mimic the approach by Page et al. (2014). By introducing a thin layer of a fullerene derivative with amine substitutions as an interlayer between the absorber layer and the metal electrode, the authors built highly efficient solar cells using a high work-function metal such as $\mathrm{Au}, \mathrm{Ag}$, or $\mathrm{Cu}$ as top electrode. In our experiments, the PEI:PCBM blend should play the role of the amine-substituted fullerene derivative. With this approach, we were able to build working solar cells with reasonable performance. However, the deposition of the PEI:PCBM layer by blade- or spin-coating was found to be very tricky. The different solubility characteristics of the two components, PEI and PCBM, required the usage of a solvent mixture, butanol and anisol. The resulting solution, however, interacted with the photoactive layer during the deposition process resulting in inhomogeneities and defects in the layer stack. All this leads to a low device preparation yield, and clearly more work is required to establish a stable and reproducible manufacturing process. Applying amine-substituted fullerene derivatives or fullerenes compatible
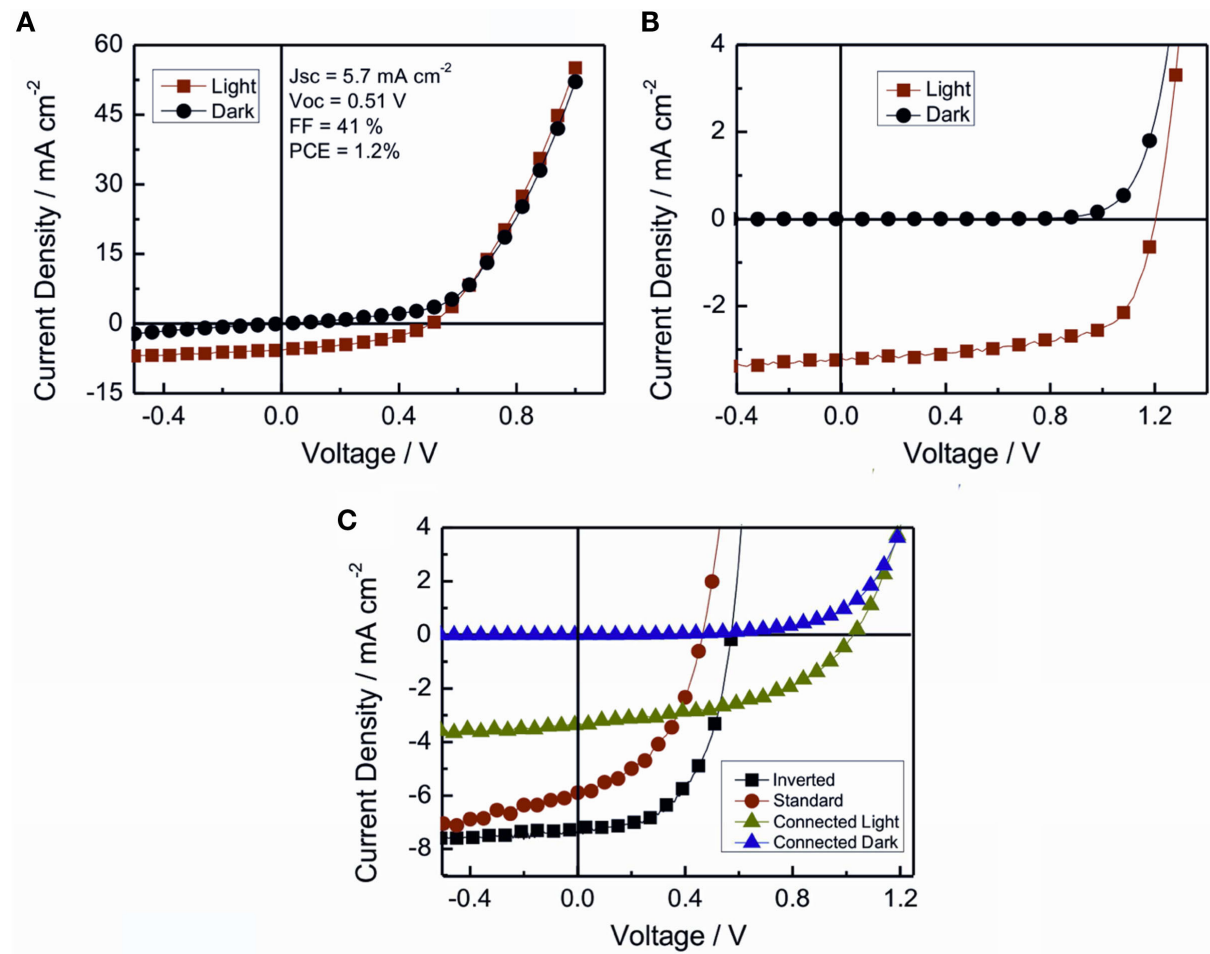

FIGURE 8 | J-V curves of (A) a standard device with a PEI:PCBM electron-selective interlayer and silver top contact, (B) a standard (glass/ITO/ PEDOT:PSS/P3HT:PCBM/LiF/AI) and an inverted (glass/ITO/PEI/P3HT:PCBM/MoO $/$ Ag) device connected in series by a common ITO electrode, (C) a standard device with a PEI:PCBM electron-selective interlayer and silver top electrode, and an inverted (glass/ITO/PEI/P3HT:PCBM/MoO $/$ Ag) device connected in series with a common ITO electrode measured combined and independently. 
with PEI solvents appear to be the most promising strategies to overcome the current limitations. The current-voltage curve of a solar cell prepared after some optimization of the PEI:PCBM formulation is shown in Figure 8A. The devices still suffers from a reduced open-circuit voltage, electrical fill factor, and photocurrent compared with typical P3HT/PCBM devices.

In the next step, we used this device architecture to build small modules based on standard and inverted solar cells processed on the same substrate.

\section{Interconnected Standard and Inverted Solar Cells}

The different device designs discussed earlier were used to test the interconnect scheme suggested in Figure 1B. Using bladecoating for the deposition of the organic layers, a standard and an inverted cell stack were fabricated on an ITO-coated substrate. In the first configuration, the standard and the inverted solar cells were based on the layer stacks glass/ITO/PEDOT:PSS/Absorber/ $\mathrm{LiF} / \mathrm{Al}$ and glass/ITO/PEI/Absorber/MoO $/ \mathrm{Ag}$, respectively. The ITO contact was acting as interconnect between the two devices. The resulting J-V curves measured with and without illumination are shown in Figure $\mathbf{8 B}$. As the devices were connected in series, the voltages delivered by the two solar cells add up yielding an open-circuit voltage of $\sim 1.2 \mathrm{~V}$. Excellent electrical fill factors in the range of $65 \%$ were observed for the interconnected inverted and standard solar cells. As the active device area is doubled, the short circuit current density is reduced by a factor of 2 . The only drawback of this configuration is that the top electrode of the standard device degrades quickly under ambient conditions and cannot be solution processed.

Figure 8C shows the individual $\mathrm{J}-\mathrm{V}$ curves of a standard and an inverted solar cell processed on the same ITO-coated substrate with the structures glass/ITO/PEDOT:PSS/Absorber/ PEI:PCBM/Ag and glass/ITO/PEI/Absorber/ $/ \mathrm{MoO}_{\mathrm{x}} / \mathrm{Ag}$ recorded under illumination and the resulting $\mathrm{J}-\mathrm{V}$ characteristics when the two devices are connected via the ITO electrode. We measured an open-circuit voltage of $0.57 \mathrm{~V}$, a fill factor of 0.55 , and a short circuit current density of $7.4 \mathrm{~mA} \mathrm{~cm}^{-2}$ for the inverted device. For the standard device with the PEI:PCBM interlayer, a $\mathrm{V}_{\text {oc }}$ of $0.46 \mathrm{~V}$, a FF of 0.46 , and a short circuit current density of $5.9 \mathrm{~mA} \mathrm{~cm}^{-2}$ were found.

For the interconnected devices, the voltages add up resulting in an open-circuit voltage of $1.03 \mathrm{~V}$ but due to the moderate performance of the involved standard device the overall performance is rather low with a FF of 0.47 and a short circuit current density of $3.33 \mathrm{~mA} \mathrm{~cm}^{-2}$ (Figure 8C). The two examples illustrate that the presented device designs allow the realization of the improved interconnection scheme proposed in Figure 1. Upon further optimization of the electron-selective (PEI:PCBM), a very simple

\section{REFERENCES}

Etxebarria, I., Ajuria, J., and Pacios, R. (2015). Solution-processable polymeric solar cells: a review on materials, strategies and cell architectures to overcome 10\%. Org. Electron. 19, 34-60. doi:10.1016/j.orgel.2015.01.014

Gaudian, R. (2010). "Photovoltaic Module," World Intellectual Property Organization, Patent Application WO2010083161 (A1).
TABLE 1 | Device parameter obtained for the indicated layer stack.

\begin{tabular}{llll}
\hline Layer stack & $\mathbf{V}_{\text {oc }} / \mathbf{V}$ & $\mathbf{F F}$ & $\mathbf{J}_{\mathbf{s c}} / \mathbf{m} \mathbf{A} \mathbf{~ c m}^{\mathbf{2}}$ \\
\hline ITO/PEDOT:PSS/Active/LiF/Alu & 0.58 & 0.62 & 7.8 \\
ITO/PEI/Active/MoO^/Ag & 0.6 & 0.62 & 8 \\
ITO/PEI/Active/PEDOT:PSS/Ag & 0.6 & 0.61 & 7.9 \\
PEDOT:PSS/PEI/Active/MoO^/Ag & 0.6 & 0.65 & 7.4 \\
PEDOT:PSS/PEI/Active/PEDOT:PSS/Ag & 0.59 & 0.5 & 6.8 \\
ITO/PEDOT:PSS/Active/PEI:PCBM/Ag & 0.51 & 0.41 & 5.7 \\
\hline
\end{tabular}

P3HT/PCBM was used as active layer.

procedure to build organic photovoltaic modules on a transparent electrode with a small number of components (PEDOT:PSS, PEI, absorber blend, and vacuum-deposited silver) appears to be feasible. The vacuum-deposited silver may also be replaced by a printed silver layer, leading to a fully printable organic photovoltaic module with improved electrical interconnects.

\section{SUMMARY}

We have explored organic bulk-heterojunctions solar cells and light-emitting diodes in the so-called standard and inverted configuration testing different interlayer materials. Obtained device parameters are summarized in Table $\mathbf{1}$.

While all tested interlayer combinations allowed the preparation of $\mathrm{BHJ}$ with reasonable performance, only a combination of ITO/PEI and $\mathrm{MoO}_{\mathrm{x}} / \mathrm{Ag}$ interlayers resulted in OLEDs with a performance comparable to the reference device. We speculate that a reduced charge injection efficiency is limiting the luminance of the other OLEDs prepared in the study. Based on the tested layer stacks, we demonstrated modules of two solar cells with alternating electrode polarity on a common electrode forming the interconnect. The proposed device architectures and the module design can be manufactured by printing and coating methods and could be a highly relevant alternative to the monolithic interconnect scheme used today.

\section{AUTHOR CONTRIBUTIONS}

GA, BM, CU, and PD prepared and characterized the solar cells and light-emitting diodes described in the manuscript. $\mathrm{CH}$ and MS supervised the research. All authors contributed to the manuscript preparation.

\section{FUNDING}

GA and MS would like to acknowledge the Austrian Research Promotion Agency (FFG) (flex!PV 838621, flex!PV_2.0 853603) for financial support. BM acknowledges financial support by the Erasmus Mundus Mobility Project GATE. 
Lee, J., Back, H., Kong, J., Park, D.-W., and Lee, K. (2012). New series connection method for bulk-heterojunction polymer solar cell modules. Sol. Energy Mater. Sol. Cells 98, 208-211. doi:10.1016/j.solmat.2011.11.008

Lenes, M., Wetzelaer, G. A. H., Kooistra, F. B., Veenstra, S. C., Hummelen, J. C., and Blom, P. W. M. (2008). Fullerene bisadducts for enhanced open-circuit voltages and efficiencies in polymer solar cells. Adv. Mater. 20, 2116-2119. doi:10.1002/ adma.200702438

Machui, F., Hösel, M., Li, N., Spyropoulos, G. D., Ameri, T., Søndergaard, R. R., et al. (2014). Cost analysis of roll-to-roll fabricated ITO free single and tandem organic solar modules based on data from manufacture. Energy Environ. Sci. 7, 2792. doi:10.1039/C4EE01222D

Markvart, T., and Castaner, L. (eds). (2005). Oxford, UK: Solar Cells. Elsevier Ltd.

Page, Z. A., Liu, Y., Duzhko, V. V., Thomas, P., Emrick, T., Russell, T. P., et al. (2014). Fulleropyrrolidine interlayers: tailoring electrodes to raise organic solar cell efficiency. Science 346, 441. doi:10.1126/science.1255826

Rand, B. P., and Richter, H. (eds). (2014). Organic Solar Cells. Boca Raton, FL: CRC Press.

Scharber, M. C. (2016). On the efficiency limit of conjugated polymer: fullerene-based bulk heterojunction solar cells. Adv. Mater. 28, 1994-2001. doi:10.1002/adma.201504914

Udum, Y., Denk, P., Adam, G., Apaydin, D. H., Nevosad, A., Teichert, C., et al. (2014). Inverted bulk-heterojunction solar cell with cross-linked hole-blocking layer. Org. Electron. 15, 997-1001. doi:10.1016/j.orgel.2014.02.009

Waldauf, C., Morana, M., Denk, P., Schilinsky, P., Coakley, K., Choulis, S. A., et al. (2006). Highly efficient inverted organic photovoltaics using solution based titanium oxide as electron selective contact. Appl. Phys. Lett. 89, 233517. doi:10.1063/1.2402890

$\mathrm{Xu}, \mathrm{T}$., and Yu, L. (2014). How to design low bandgap polymers for highly efficient organic solar cells. Mater. Today 17, 11-15. doi:10.1016/j.mattod.2013. 12.005

Zhao, J., Li, Y., Yang, G., Jiang, K., Lin, H., Ade, H., et al. (2016). Efficient organic solar cells processed from hydrocarbon solvents. Nat. Energy 1, 15027. doi:10.1038/nenergy.2015.27

Zhou, Y., Fuentes-Hernandez, C., Shim, J., Meyer, J., Giordano, A. J., Li, H., et al. (2012). A universal method to produce low-work function electrodes for organic electronics. Science 336, 327-332. doi:10.1126/science. 1218829

Conflict of Interest Statement: The authors declare that the research was conducted in the absence of any commercial or financial relationships that could be construed as a potential conflict of interest.

Copyright (c) 2016 Adam, Munkhbat, Denk, Ulbricht, Hrelescu and Scharber. This is an open-access article distributed under the terms of the Creative Commons Attribution License (CC BY). The use, distribution or reproduction in other forums is permitted, provided the original author(s) or licensor are credited and that the original publication in this journal is cited, in accordance with accepted academic practice. No use, distribution or reproduction is permitted which does not comply with these terms. 